\title{
Delayed Treatment and Missed Opportunities for Limb Salvage in Patients with Peripheral Arterial Embolism
}

\author{
Lefter Nasto*, Tanyo Kavrakov \\ Clinic of Vascular Surgery, University Hospital, Trakia University, Stara Zagora, Bulgaria
}

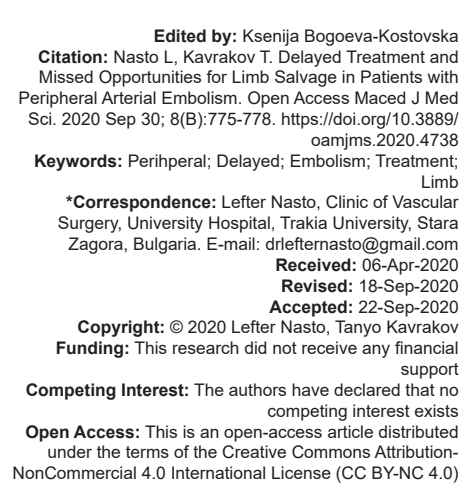

\section{Introduction}

The peripheral arterial embolism (PAE) is a sudden decrease in limb perfusion due to acute occlusion of peripheral artery which leads to ischemic tissue damage that can threaten the limb of a patient and requires immediate revascularization. It is estimated that the incidence of acute limb embolism in the general population is around $14 / 100,000$ inhabitants per year [1].

Accurate and timely diagnosis is crucial to salvage the patient's limb and sometimes the patient's life.

In cases of complete arterial occlusion and absence of collateral perfusion, irreversible damage can occur within 4-6 h [2], [3], [4].

\begin{abstract}
BACKGROUND: The peripheral arterial embolism (PAE) is a sudden decrease in limb perfusion due to acute (the ischemic tissue damage, that can threaten the limb of atient and requires immediate revascularization. It is estimated that the incidence of acute limb emoblism in the general population is around 14/100,000 inhabitants per year. Accurate and timely diagnosis is crucial to salvage the patient's (occur within 4 to 6 hours. The fundamental definition for treatment of acute peripheral arterial embolism is revascularisation. Revascularisation is either performed endovascularly or by an open surgical
\end{abstract}

AIM: Our study aims to identify medical consultations and cardiovascular assessments undergone by patients in the

RESULTS: Following exclusion, 424 patients (mean age $68.5 \pm 5.85$ years) were included. 159 patients $(66.8 \%)$ 作 作 at the discharge, $11.3 \%$ of the studied cohort were with minimal post-treatment complains (numbness, coldness,

CONCLUSION: The consequences of acute limb embolism such as prolonged hospitalization, major limb amputation, and/or death have a profound socioeconomic impact. Unrecognition of this vascular pathology and differential diagnosis difficulties are possibly leading factors for delayed or missed treatment. 
Delays in the management of acute peripheral arterial ischemia due to an embolism are common and associated with poor limb salvage outcomes.

In aging population, primary major amputations (AMP, below-knee or above-knee) continue to be performed despite advances in revascularization. A hypothesis that not only patient comorbidities but also the system of health-care delivery affected the treatment of patients with acute arterial limb ischemia could be eligible [11].

At present, there are suspicions whether opportunities for timely recognition in general practice and other more specialized medical practice exist and are potentially being delayed or missed. Our study aims to identify medical consultations and cardiovascular assessments undergone by patients in the period before being hospitalized, to evaluate for missed or delayed opportunities for diagnosis.

\section{Methods}

Retrospective cohort study utilize the medical documentation and previous outpatient or in hospital consultations. Adult patients undergone treatment due to PAE were identified and analyzed.

Patients were identified through the administrative hospital database using the International Classification of Diseases, $10^{\text {th }}$ revision (ICD-10) codes "Embolism and thrombosis of arteries of upper extremities," - I74.2, 174.3 - "Embolism and thrombosis of arteries of the lower extremities," I74.5 - "Embolism and thrombosis of iliac artery," and 174.0 - "Embolism and thrombosis of abdominal aorta."

Hospitalized patients with those medcodes between January 1, 2010, and March 1, 2020, were recorded.

Gama CodeMasters - an administrative hospital database was used to exclude patients treated due to acute post-traumatic arterial ischemia or acute ischemia due to peripheral arterial disease (PAD).

The total number of outpatient examinations, hospital treatment, and their latest consultation before admission was identified.

\section{Results}

Following exclusion, 424 patients (mean age $68.5 \pm 5.85$ years) were included. About $45.9 \%$ of the cohort were recorded as having arterial hypertension as most common comorbidity followed by atrial fibrillation in $33.5 \%$ of the cases. About $56 \%$ (238 patients) presented in our clinic more than $12 \mathrm{~h}$ after onset of the symptoms, 159 patients $(66.8 \%)$ had visited their family doctors or other medical specialist before admission and in all of the cases was initiated therapeutic approach. The rest of the cohort 79 patients $(33.2 \%)$ presented lately due to other social reasons.

The group of 159 patients that admitted lately due to medical indications - diagnostic, health care administrative or treatment-related problems is subject of our study. The largest group including 113 (71\%) patients was treated outpatient by vascular surgeons with preventative medications as followed: Antiplatelet (79.6\%), vasoactive (76.1\%), analgetics $(62.8 \%)$, and lipid lowering agents (31.8\%) with poor outcome. This group represented major interest for our study to analyze and investigate the reasons for late referring to vascular surgery department and, respectively, delays in treatment. Physical state and clinical stage of the extremity in all of 113 cases treated outpatient by vascular surgeons are presented in Table 1 based on clinical stage according to the Rutherford recommended standards for reporting lower extremity ischemia.

\section{Table 1: Distribution of the stages}

\begin{tabular}{ll}
\hline Stages & 113 patients \\
\hline I stage (Viable ischemia) & $18(15.9 \%)$ \\
II-a stage (Threatened marginal) & $27(23.9 \%)$ \\
II-b stage (Threatened: Immediate) & $35(31 \%)$ \\
III stage (Irreversible) & $33(29.2 \%)$ \\
\hline
\end{tabular}

The largest number of patients referred lately to our clinic was with threatened marginal ischemia, 24 of them $68.5 \%$ had PAD as a primary comorbidity. In all of the cases, treatment approach was initiated with vasoactive medications due to suspicion of CLI.

Age, comorbidities, risk factors, and medication use of the 113 patients treated outpatient by vascular surgeons are presented in Table 2.

Table 2: Age, comorbitidies, risk factors and medication use

\begin{tabular}{ll}
\hline Variables & 113 patients \\
\hline Age $>70$ years & $76(67.2 \%)$ \\
Hypertension & $68(60.1 \%)$ \\
Diabetes & $43(38.05 \%)$ \\
Smokers & $42(37.1 \%)$ \\
Peripheral arterial disease & $64(56.6 \%)$ \\
Cardiac pathology (AF, CAD, CHF, and incl. past myocardial infarction) & $52(46.01 \%)$ \\
Cerebrovascular disease & $39(34.5 \%)$ \\
Medication use (before admission) & $90(79.6 \%)$ \\
\hline
\end{tabular}

Seventeen patients $(10.6 \%)$ were directed outpatient to orthopedic surgeon due to suspicion of trauma, after reviewing medical documentations and clinical data provided by patients in all of the cases history of trauma were absent.

Fifteen patients $(9.4 \%)$ were treated by their family doctors with pain relief medications.

The rest of the 14 patients (8.8\%) were treated by neurosurgeons or neurologists due to a suspicion of cauda equina and other neuropathies, all 14 patients of these group were treated in hospital. In these group was registered worse mortality rate $28.5 \%$ (4 of 14 ), all 4 death cases were with aortic 
saddle embolism untreated at least $15 \mathrm{~h}$ from onset of the symptoms.

Treatment approach in all 159 patients is presented in Table 3 . About $61 \%$ of the patients despite the delay underwent embolectomy alone.

Table 3: Treatment approach

\begin{tabular}{ll}
\hline Treatment approach & $\mathrm{n}=159$ \\
\hline Embolectomy alone & $97(61 \%)$ \\
Embolectomy + other arterial reconstruction (bypass, TEA, etc.) & $21(13.2 \%)$ \\
Embolectomy + minor amputation & $9(5.7 \%)$ \\
Primary major amputation & $16(10 \%)$ \\
MAT & $1(0.6 \%)$ \\
Thrombolysis & $1(0.6 \%)$ \\
Conservative treatment & $14(8.9 \%)$ \\
\hline
\end{tabular}

In 21 cases, embolectomy was insufficient and was amplified by other arterial reconstruction (aorta-femoral bypass in 1 patient, indirect iliac endarterectomy in 6 cases, Common femoral artery (CFA), and profunda femoral artery (PFA) endarterectomy in 9 cases, and in 5 occasions was performed femoropopliteal bypass above the knee). Sixteen patients due to the irreversible ischemia underwent primary major amputation, in $5.7 \%$ despite successfully performed embolectomy, the necessity of minor amputation was present. One patient was treated with mechanical aspiration thrombectomy and also one patient underwent thrombolysis.

Fourteen patients due to a viable compensated ischemia and because of very high operative risk were treated conservatively.

Post-treatment outcome and overall mortality are presented in Table 4.

Table 4: Post-treatment outcome and overall mortality

\begin{tabular}{ll}
\hline Outcome & $\mathrm{n}=159$ \\
\hline Free of complains & $108(67.9 \%)$ \\
$\begin{array}{l}\text { Minimal complains (numbness, coldness, absent peripheral pulsations, } \\
\text { claudication) }\end{array}$ & $18(11.3 \%)$ \\
Amputation & $23(14.4 \%)$ \\
Rethrombosis & $14(8.8 \%)$ \\
Recurrent embolism & $6(3.7 \%)$ \\
Fasciotomy & $19(11.9 \%)$ \\
Operative site infection & $7(4.4 \%)$ \\
Death (in hospital or 30 deaths post-submission) & $21(13.2 \%)$ \\
\hline
\end{tabular}

The majority of the patients 108 (67.9\%) were free of complains at the discharge, $11.3 \%$ of the studied cohort were with minimal post-treatment complains (numbness, coldness, absent peripheral pulsations, and insignificant claudication). Amputation rate was $14.4 \%$, incidence of rethrombosis $8.8 \%$, and recurrent embolism frequency around $3.7 \%$. Death was registered in 21 cases $(13.2 \%)$.

\section{Discussion}

Acute PAE is a vascular pathology that can be diagnosed and treated in a short time. Mortality and morbidity are significantly reduced after timely and accurate diagnosis and treatment.

Delayed diagnosis in certain cases may be caused by clinical course of the embolism hidden under the guise of a post-operative condition or a severe comorbid state [12].

Pre-transfer management decisions by referring hospitals to an academic tertiary care facility for ALI patients occur less frequently than expected and are associated with an increased adverse event [13].

Furthermore, a potential difficulty in differentiating between PAE and acute peripheral arterial thrombosis in patients with pre-existing PAD could be a major cause of delayed treatment in acute emboligenic occlusion [14].

A study showed that the greatest source of delay is time from symptom onset to presentation in the emergency department (ED); an average of $11.35 \mathrm{~h}$. The second largest source of delay was time from recognition of PAE to imaging, with an average delay of $4.75 \mathrm{~h}$. The average ED evaluation time was $40 \mathrm{~min}$, and the average total time to intervention was $10.2 \mathrm{~h}$. While time to symptom presentation may represent a failure of public health, time to imaging was identified as an area of unacceptable delay by the authors [15].

A swede study examined the effect of prehospital care on the time to treatment. Persons who were transported through emergency medical services (EMSs) arrived to the hospital at a median time of 5 $\mathrm{h}$ after symptom onset, were seen by a physician at a median time of $51 \mathrm{~min}$, and had revascularization at a median time of $23 \mathrm{~h}$. Those not transported by EMS arrived to the hospital at a median time of $48 \mathrm{~h}$ after symptom onset, were seen by a physician at a median time of $80 \mathrm{~min}$, and had revascularization at a median time of $93 \mathrm{~h}$ [16]. In a condition where minutes matter, expedient action is critical. Time to recognition, imaging, consultation, and intervention all are potential sources of delay [17].

It is uncertain in our study group if the opportunities for timely diagnosis have "just been missed" or it concerns a group of patients being improperly treated due to health-care system problems, poor preparation of medical specialists regarding vascular pathologies or due to a lack of a unified standard for the treatment of vascular diseases.

\section{Conclusion}

The consequences of acute limb embolism such as prolonged hospitalization, major limb amputation, and/or death have a profound socioeconomic impact.

Unrecognition of this vascular pathology and differential diagnosis difficulties is possibly leading factors for delayed or missed treatment.

Further research is required to analyze and understand the cause for these opportunities being 
delayed or missed and to develop strategies that would prevent future complications and amputations.

\section{References}

1. Norgren L, HiattWR, Bell K, Nehler MR, Harris KA, Fowkes FG, etal. Inter-society consensus for the management of peripheral arterial disease (TASC II). Eur J Vasc Endovasc Surg. 2007;33(Suppl 1):S1-75. https://doi.org/10.1016/j.ejvs.2006.09.024 PMid: 17140820

2. Henke PK. Contemporary management of acute limb ischemia: Factors associated with amputation and in-hospital mortality. Semin Vasc Surg. 2009;22(1):34-40. https://doi.org/10.1053/j. semvascsurg.2009.01.002

\section{PMid:19298934}

3. Jivegård L, Bergqvist $D$, Holm J. When is urgent revascularisation unnecessary for acute lower limb ischaemia? Eur J Vasc Endovasc Surg. 1995;9(4):448-53. https://doi.org/10.1016/ s1078-5884(05)80014-0

\section{PMid:7633991}

4. Earnshaw J. Acute Ischaemia: Evaluation and Decision Making Rutherford's Vascular Surgery. $7^{\text {th }}$ ed. Philadelphia, Pennsylvania, PA: Saunders Elsevier; 2010. p. 2389-98.

5. Wicky S, Pinto EG, Oklu R. Catheter-directed thrombolysis of arterial thrombosis. Semin Thromb Hemost. 2013;39(4):441-5. https://doi.org/10.1055/s-0033-1334482

PMid:23483456

6. Sedghi Y, Collins TJ, White CJ. Endovascular management of acute limb ischemia. Vasc Med. 2013;18(5):307-13. https://doi. org/10.1177/1358863×13505643

\section{PMid:24097417}

7. Larena-Avellaneda A, Debus ES, Kolbel T, Wipper S, Diener H Acute ischemia and bypass occlusion: Current options. J Cardiovasc Surg (Torino). 2014;55(2 Suppl 1):187-94. PMid:24796913

8. Creager MA, Kaufman JA, Conte MS. Clinical practice. Acute limb ischemia. N Eng J Med. 2012;366(23):2198-206. https:// doi.org/10.1056/nejmcp1006054

\section{PMid:22670905}

9. Jaffery Z, Thornton SN, White CJ. Acute limb ischemia. Am J Med Sci. 2011;342(3):226-34. https://doi.org/10.1097/ maj.0b013e31820ef345

PMid:21642824

10. Santistevan JR. Acute limb ischemia: An emergency medicine approach. Emerg Med Clin North Am. 2017;35(4):889-909. https://doi.org/10.1016/j.emc.2017.07.006 PMid:28987435

11. Abou-Zamzam AM Jr, Gomez NR, Molkara A, Banta JE, Teruya TH, Killeen JD, et al. A prospective analysis of critical limb ischemia: Factors leading to major primary amputation versus revascularization. Ann Vasc Surg. 2007;21(4):458-63. https://doi.org/10.1016/j.avsg.2006.12.006 PMid: 17499967

12. Yamada T, Yoshii T, Yoshimura H, Suzuki K, Okawa A. Upper limb amputation due to a brachial arterial embolism associated with a superior mesenteric arterial embolism: A case report. BMS Res Notes. 2012;5:372. https://doi.org/10.1186/1756-0500-5-372 PMid:22828325

13. Wang SK, Murphy MP, Gutwein AR, Drucker NA, Dalsing M, Motaganahalli RL, et al. Perioperative outcomes are adversely affected by poor pretransfer adherence to acute limb ischemia practice guidelines. Ann Vasc Surg. 2018;50:46-51. https://doi. org/10.1016/j.avsg.2017.11.050 PMid:29477682

14. Shin HS, Kyoung KH, Suh BJ, Jun SY, Park JK. Acute limb ischemia: Surgical thromboembolectomy and the clinical course of arterial revascularization at ankle. Int J Angiol. 2013;22:10914. https://doi.org/10.1055/s-0033-1336827 PMid:24436594

15. Normahani P, Standfield NJ, Jaffer U. Sources of delay in the acute limb ischemia patient pathway. Ann Vasc Surg. 2017;38:279-85. https://doi.org/10.1016/j.avsg.2016.05.118

16. Langenskiöld M, Smidfelt K, Karlsson A, Bohm C, Herlitz J, Nordanstig J. Weak links in the early chain of care of acute lower limb ischaemia in terms of recognition and emergency management. Eur J Vasc Endovasc Surg. 2017;54(2):235-40. https://doi.org/10.1016/j.ejvs.2017.04.010 PMid:28583719

17. Baker S, Deircks D. Acute limb ischemia. Emerg Med. 2018;50(3):65-71. 